\title{
The Aboriginal Population Health Training Initiative: a NSW Health program established to strengthen the Aboriginal public health workforce
} \author{
Lisa K McCalluma and Andrew Milata \\ ${ }^{a}$ Centre for Epidemiology and Evidence, NSW Ministry of Health, Sydney, Australia \\ b School of Public Health and Community Medicine, UNSW Sydney, Australia \\ c Western Sydney Local Health District, NSW, Australia \\ ${ }^{d}$ Corresponding author: darne@moh.health.nsw.gov.au
}

Ben Lia , Aaron Cashmore ${ }^{a, b}$, Dawn Arnemanª, Wendy Bryan-Clothier ${ }^{\mathrm{c}}$,

\section{Article history}

Publication date: October 2017 Citation: Li B, Cashmore A, Arneman D, Bryan-Clothier W, McCallum LK, Milat A. The Aboriginal Population Health Training Initiative: a NSW Health program established to strengthen the Aboriginal public health workforce. Public Health Res Pract. 2017;27(4):e2741739. https://doi.org/10.17061/phrp2741739

\section{Key points}

- Strengthening the Aboriginal health workforce is important for improving Aboriginal health in Australia

- The Aboriginal Population Health Training Initiative (APHTI) was established by NSW Health in 2011 to provide comprehensive, competency-based public health training exclusively for Aboriginal people

- APHTI has made an important contribution to strengthening the New South Wales Aboriginal public health workforce, with nine health services hosting trainees and nine people graduating

- The program has a high retention rate of 17 out of 18 trainees

\section{Abstract}

Objectives: Increasing the representation of Aboriginal people in the health workforce can contribute to improving Aboriginal people's health and wellbeing by supporting the provision of more culturally appropriate health programs and services. The Aboriginal Population Health Training Initiative aims to strengthen the Aboriginal public health workforce in New South Wales (NSW), with the long-term goal of improving the health of Aboriginal people.

Type of program or service: The program provides comprehensive, competency-based public health training for Aboriginal people.

Methods: Participants undertake a series of work placements in public health, and complete a Master of Public Health degree.

Results: A 2014 evaluation demonstrated that the program makes an important contribution to strengthening the NSW Aboriginal public health workforce. Trainees reported a high level of satisfaction with the quality of their work placements, the flexibility of the program to support their work and study, and efforts made to ensure the program's cultural safety. The program has a high trainee retention rate (17 of 18 trainees), and all graduates have successfully gained employment within the NSW health system.

Lessons learnt: Three key factors contribute to the success of the program: trainees undertake their training within their communities; the structure promotes the direct application of learning through simultaneous work and study; and the NSW Government shows strong leadership and support. 


\section{Introduction}

In Australia, Aboriginal people experience shorter life expectancies, greater rates of disability and reduced quality of life compared with non-Aboriginal people. ${ }^{1}$ Working in partnership with Aboriginal people to close the gap in health outcomes between Aboriginal and nonAboriginal people is a priority of the New South Wales (NSW) Government. ${ }^{2}$

Several sociopolitical and environmental factors contribute to worse health outcomes for Aboriginal people. ${ }^{3}$ One significant issue is the suboptimal engagement of some Aboriginal people with the mainstream health system. ${ }^{4}$ This has been linked to a lack of cultural competency in the delivery of health programs and services. ${ }^{4}$ As a result, Aboriginal people are more likely to present with advanced and comorbid diseases, contributing to poorer health outcomes. ${ }^{5}$

Increasing the representation of Aboriginal people in the health workforce can help overcome Aboriginal health inequities by supporting the provision of more culturally appropriate health services. ${ }^{6-7}$ Although Aboriginal people make up $2.9 \%$ of the NSW population, Aboriginal people represented only $2.5 \%$ of the NSW Health workforce in 2016. . 8,9 Underrepresentation of Aboriginal people in the health workforce limits the ability of the NSW health system to meet the needs of Aboriginal communities. ${ }^{7}$

Attracting, developing and supporting more Aboriginal people to work in the health sector is a key priority of NSW Health. ${ }^{2}$ In line with this priority, NSW Health established the Aboriginal Population Health Training Initiative (APHTI) to strengthen the Aboriginal workforce with suitably trained and skilled public health practitioners. ${ }^{10}$ Although a number of Australian universities offer postgraduate public health courses tailored to meet the needs of Aboriginal people ${ }^{11}$, the APHTI combines workplace, competency-based public health training with postgraduate study. This enables trainees to develop new skills and acquire the experience needed to become leaders in population health. The program was developed based on integration of common characteristics among successful workplacebased training programs, such as a balance between work placements and study at an accredited university, exposure to a range of work and learning environments, and strong leadership from the government. ${ }^{12-13}$ In this paper, we describe the development, implementation and evaluation of the APHTI.

\section{The NSW Aboriginal Population Health Training Initiative (APHTI)}

The APHTI is a 3-year public health training program for Aboriginal people. Participants undertake a series of supervised work placements in population health and complete a Master of Public Health (MPH) degree. ${ }^{10}$ The APHTI aims to strengthen the Aboriginal public health workforce in NSW, with the long-term goal of improving the health of Aboriginal people.

The program is delivered through partnerships between the NSW Ministry of Health and NSW health services (collectively known as NSW Health); the Ministry coordinates the program, and health services employ and host trainees. Trainees spend on average 4 days a week undertaking project work in supervised work placements and 1 day a week studying. Work placements provide trainees with practical experience in a range of different population health areas, including communicable diseases, health promotion, epidemiology, and environmental health.

A key feature of the APHTI is that trainees are employed within their chosen health service. Respecting the commitments of Aboriginal people towards their families and communities, the APHTI does not require trainees to relocate for work or study. Rather, the APHTI is focused on ensuring that trainees can work and study in environments that are most conducive to their learning.

\section{Development of the APHTI}

In 2009, an advisory committee was established to guide the development of the APHTI. This committee included representatives from the NSW Ministry of Health, NSW health services, the Aboriginal Health \& Medical Research Council of NSW, universities in NSW offering public health programs, and other organisations representing Aboriginal and rural health interests in NSW. The committee oversaw an extensive literature review ${ }^{14}$, which identified pertinent characteristics of successful training programs and informed the development of a program structure that was sensitive to the needs of Aboriginal people.

The APHTI began in 2011 with a pilot group of four trainees. Following positive feedback from trainees and supervisors, traineeships were established in other NSW health services. The program continues to offer up to four new traineeships each year, with 18 trainees recruited since 2011.

\section{APHTI framework}

Underpinning the training program is the constructive alignment model, in which the participant constructs meaning from their learning in an environment that supports them to reach their desired outcomes. ${ }^{15}$ The self-driven learning of APHTI participants is guided by a competency framework ${ }^{16}$, which includes eight core competency areas (Figure 1).

The competency areas are intended to be fostered and applied in a work environment where the trainees feel safe to express their identity as Aboriginal people and generally feel that Aboriginal culture is respected, understood and supported. ${ }^{17}$ The competency framework aims to support a consistent quality of 
Figure 1. Relationship between competency areas of the NSW Aboriginal Population Health Training Initiative and their delivery in an environment of cultural respect that recognises trainee wellbeing

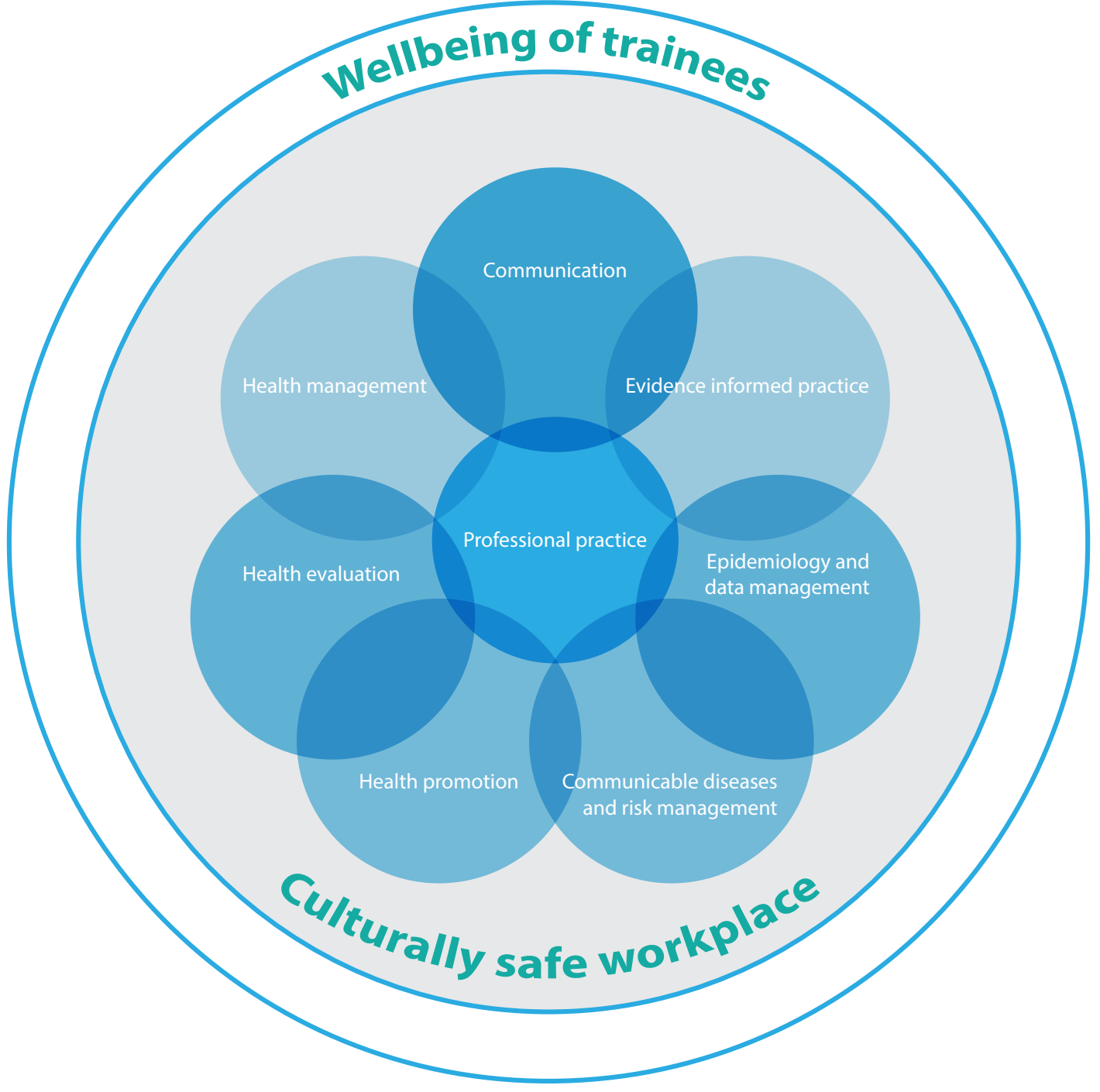

learning experience. It provides standards against which participants can be assessed to ensure they are competent public health practitioners. Furthermore, the framework supports academic learning by encouraging trainees to apply new knowledge and skills gained through their MPH studies in the workplace.

The program is supported by a dedicated full-time program coordinator, whose role is to actively ensure that the needs of trainees are being met. The coordinator regularly liaises with trainees to identify and address any issues and concerns. Regular formal feedback sessions are also used to inform the development of the program, understand trainees' learning experiences and address trainees' needs.

Trainees are also supported by a local health service coordinator and supervisor at each work placement and, in many cases, a mentor. All staff who support the trainees complete cultural competency training to ensure that they understand how to provide guidance to trainees in culturally respectful ways. Finally, trainees attend group professional development activities, which aim to foster relationships and facilitate a culture of peer support.

\section{Evaluation of the APHTI}

A 2014 evaluation was conducted to identify achievements and challenges in the implementation of the APHTI and measure its effect on strengthening the Aboriginal public health workforce. ${ }^{17}$ Ethical approval for the evaluation was granted by the Aboriginal Health \& Medical Research Council Ethics Committee (application number 1026/14). The evaluation included:

1. Interviews to explore the experiences of 31 key stakeholders including trainees $(n=11)$, health service coordinators and supervisors $(n=8)$, Ministry of Health staff $(n=5)$, advisory committee members $(n=5)$, and others $(n=2)$

2. Analysis of program documents, including the competency framework, assessment resources and materials developed for NSW health services 
3. Analysis of participant outcomes, including exit interviews, academic transcripts and assessment reports.

Overall, stakeholders reported a positive experience with the APHTI. All trainees reported being pleased to have entered the program and thought it was beneficial to their career development. In particular, trainees reported a high level of satisfaction with the quality of their work placements, the flexibility of the program to support their balance of work and study, the guidance received from supervisors and coordinators, and efforts made to ensure that the program was culturally safe. Most health service stakeholders were also satisfied with their experience of the APHTI and would consider future engagement of trainees. To date, the program has maintained a high trainee retention rate, with current trainees and graduates representing 17 of the 18 participants.

Inconsistencies in employment conditions and postprogram job security were a source of concern for trainees. However, employment outcomes have so far been positive, with all graduates securing positions within NSW Health.

Trainees in the first cohort reported difficulties in applying the competency framework to their work, but later trainees reported fewer difficulties. This was largely attributed to increased support from the Ministry and learning from the experiences of previous trainees.

Some trainees found elements of the university coursework and workplace requirements challenging, especially where higher-level maths was required. This meant that some trainees required more support than anticipated, although workplace supervisors indicated the general experience of providing support to APHTI trainees was positive.

The evaluation and current program outcomes show the APHTI has been successful in achieving its stated objectives:

1. Increasing the number of Aboriginal people with postgraduate qualifications in population health eight trainees have successfully completed an MPH, and nine trainees are working towards this

2. Increasing the number of Aboriginal people who have completed public health workplace competencies - eight trainees successfully completed a final assessment and met all the requirements of the APHTI competency framework

3. Increasing the exposure of the organisation's population health units and workforce to the value of traineeships - nine NSW health services hosted APHTI trainees

4. Increasing Aboriginal staff exposure to career opportunities in population health - 18 trainees completed a range of population health placements and projects

5. Creating a more adaptive and competent Aboriginal population health workforce - nine trainees have secured employment in population health and management roles within NSW Health.

\section{Conclusions and implications}

The APHTI is a successful, comprehensive public health training program exclusively for Aboriginal people. The program was established as part of a commitment by the NSW Government to reduce disparities in health outcomes between Aboriginal and non-Aboriginal people in NSW. Increased education and employment opportunities for Aboriginal people can increase income and individual, family and community capacity. This also increases their capacity to engage with the health system, both as employees and health consumers. Improved health system engagement can lead to increased access to medical and preventive healthcare in a timely manner, thereby enhancing health.

Three elements were identified as critical to the success of the APHTI:

1. Enabling trainees to stay within their communities

2. A structure that enables trainees to work and study simultaneously to develop skills and achieve competencies

3. Strong leadership and support from the NSW Government.

Regular evaluation will be undertaken to monitor the function and outcomes of the program. The employment and educational outcomes of APHTI graduates are excellent, though it is important to note that only nine participants have completed the program to date. Furthermore, the trainees and hosting health services are satisfied with the implementation of the APHTI.

The APHTI could be a useful model for guiding the development of similar programs in other jurisdictions across Australia to strengthen the nation's Aboriginal public health workforce.

\section{Acknowledgements}

The authors would like to thank members of the APHTI Advisory Committee, current and past APHTI trainees and participating NSW health services for their ongoing support of the initiative.

\section{Competing interests}

None declared

\section{Author contributions}

$\mathrm{BL}$ was responsible for the conception of the paper, interpretation of data, drafting and editing of the manuscript. AC was responsible for the conception of the paper, interpretation of data, revising and editing of the manuscript. WB-C was responsible for the interpretation of data, revising and editing of the manuscript. DA was responsible for the conception of the paper, interpretation of data, revising and editing of the manuscript. LM was responsible for the interpretation of data, revising 
and editing of the manuscript. AM was responsible for the conception of the paper, revising and editing of the manuscript.

\section{References}

1. Centre for Epidemiology and Evidence. The health of Aboriginal people of NSW. Report of the Chief Health Officer, 2012. Sydney: NSW Ministry of Health; 2012 [cited 2016 May 19]. Available from: www.health.nsw. gov.au/epidemiology/Publications/Aboriginal-HealthCHO-report.pdf

2. NSW Ministry of Health. NSW Aboriginal health plan 2013-2023. Sydney: NSW Ministry of Health; 2012 [cited 2016 May 19]. Available from: www1.health.nsw.gov.au/ pds/ActivePDSDocuments/PD2012_066.pdf

3. Shepherd CC, Li J, Zubrick SR. Social gradients in the health of Indigenous Australians. Am J Public Health. 2012;102(1):107-17.

4. McBain-Rigg KE, Veitch C. Cultural barriers to health care for Aboriginal and Torres Strait Islanders in Mount Isa. Aust J Rural Health. 2011;19(2):70-4.

5. Gibberd A, Supramaniam R, Dillon A, Armstrong BK, O'Connell DL. Are Aboriginal people more likely to be diagnosed with more advanced cancer? Med J Aust. 2015;202(4):195-9.

6. Sullivan LW. Missing persons: minorities in the health professions, a report of the Sullivan Commission on Diversity in the Healthcare Workforce. Atlanta: The Sullivan Commission; 2004 [cited 2016 May 19]. Available from: health-equity.lib.umd.edu/40/1/Sullivan_ Final_Report_000.pdf

7. Curtis E, Wikaire E, Stokes K, Reid P. Addressing indigenous health workforce inequities: a literature review exploring 'best' practice for recruitment into tertiary health programmes. Int J Equity Health. 2012;11:13.

8. NSW Health. Good health - great jobs: Aboriginal Workforce Strategic Framework 2016 - 2020. Sydney: NSW Health; 2016 [cited 2016 Dec 12]. Available from: www1.health.nsw.gov.au/pds/ActivePDSDocuments/ PD2016_053.pdf

9. Australian Bureau of Statistics. Canberra: ABS, 2017. Estimates of Aboriginal and Torres Strait Islander Australians, June 2011; 2013 [cited 2016 May 24]; [about 6 screens]. Available from: www.abs.gov.au/ausstats/ abs@.nsf/mf/3238.0.55.001
10. NSW Government. Health. Sydney: NSW Health; 2017. NSW Aboriginal Population Health Training Initiative; [cited 2016 May 19]; [about 2 screens]. Available from: www.health.nsw.gov.au/training/aphti/Pages/default.aspx

11. Australian Indigenous HealthInfoNet. Perth: Australian Indigenous HealthlnfoNet; 2017. Courses and training; [cited 2017 Aug 18]; [about 35 screens]. Available from: www.healthinfonet.ecu.edu.au/key-resources/coursestraining

12. ARTD Consultants. Evaluation of the NSW Aboriginal Mental Health Worker Training Program. Final report executive summary. Sydney: ARTD Consultants; 2013 [cited 2016 May 19]. Available from: www.health.nsw. gov.au/mhdao/workforcedev/Documents/ARTD-ExecSummary.PDF

13. NSW Health. Review of the NSW Health Aboriginal Environmental Health Officer Training Program. Sydney: NSW Health; 2010 [cited 2016 May 19]. Available from: www.health.nsw.gov.au/environment/Publications/ aboriginal-training.pdf

14. O'Sullivan B. A discussion of workplace based population health competencies and their application to the Aboriginal Population Health Training Initiative. Sydney: NSW Department of Health, 2010 (unpublished).

15. Biggs J. Enhancing teaching through constructive alignment. High Educ. 1996;32(3):347-64.

16. Ridoutt L, Pilbeam V, O'Sullivan B, Madden DL, Wise MJ, Meyer L, Cumming G. Competency framework of the NSW Aboriginal Population Health Training Initiative. Sydney: NSW Ministry of Health; 2012 [cited 2016 May 31]. Available from: www.health.nsw. gov.au/training/aphti/Publications/APHTI-competencyframework.pdf

17. Powers \& Associates. NSW Aboriginal Population Health Training Initiative (APHTI) evaluation. Sydney: Powers and Associates; 2015 [cited 2017 Mar 20]. Available from: www.health.nsw.gov.au/research/Documents/aphtievaluation-final-report.pdf

\section{Copyright: (c)}

(C) $2017 \mathrm{Li}$ et al. This article is licensed under the Creative Commons Attribution-NonCommercial-ShareAlike 4.0 International Licence, which allows others to redistribute, adapt and share this work non-commercially provided they attribute the work and any adapted version of it is distributed under the same Creative Commons licence terms. See: www.creativecommons.org/licenses/by-nc-sa/4.0/ 